\section{Dark-Light Treatments Influence Induction of Tomato Anther Callus}

\author{
J. Jaramillo ${ }^{1}$ and W.L. Summers ${ }^{2}$ \\ Department of Horticulture, Iowa State University, Ames, IA 50011
}

Additional index words. Lycopersicon esculentum, anther culture

\begin{abstract}
Three tomato (Lycopersicon esculentum Mill.) cultivars were studied to determine the effect of nine dark-light regimes on anther callus initiation and growth. Prophase I (leptotene) stage anthers of 'L-680A', 'Licato', and 'Ailsa Craig' were plated on Doy's basal medium 1 and provided with 2 to 10 weeks of dark treatment. After each dark period, each plate was transferred to a 16-hour photoperiod for the duration of the 10-week experiment. At this time, the number of anthers producing calli and the diameter of the calli produced were recorded. Callus number and diameter increased as the dark period duration increased. Callus diameter peaked at 8 weeks of dark treatment for 'Ailsa Craig' and 'Licato', whereas ' $\mathrm{L}-680 \mathrm{~A}$ ' calli continued to grow over the entire 10-week dark treatment. Although the number and size of callus may continue to increase past 8 weeks of dark incubation, callus quality and appearance decreased noticeably during this period. For each additional week of dark period exposure, $7 \%$ more of the plated anthers produce callus, and callus diameter increases by $0.27 \mathrm{~mm}(12 \%$ of total growth).
\end{abstract}

Light is known to influence the rates of cell division (Fraser et al., 1967; George and Sherrington, 1984) and ethylene evolution (Huxter et al., 1981), which, in turn, may influence caulogenesis and rhizogenesis (Cornejo-Martin et al., 1979). Therefore, the duration and timing of light application play an important role in explant morphogenesis (Noth and Abel, 1971). Previous studies indicate that an alternating period of dark-light exposure using white light is superior to a continuous photoperiod or monochromatic red light. For example, dark-treated Datura anthers produced more embryoids when transferred to white light (Sopory and Maheswhari, 1976). Rice (Oryza sativa L.) anthers must be incubated in the dark for at least 3 weeks before light exposure (Niizeki and Oono, 1968; Noth and Abel, 1971). However, dark exposure may be associated with negative effects in some species. $\mathrm{Ni}$ cotiana tabacum anthers produced less callus and fewer embryoids when incubated in the dark than in light (Noth and Abel, 1971; Sunderland, 1971).

To date, there is no generalized procedure for the production of both callus and shoots from tomato anthers. Typically, tomato anthers have been either incubated under coolwhite light (2000 to $20,000 \mathrm{~lx}$ ) for $12 / 12$ or $8 / 16$ h dark/light photoperiods (Kut et al., 1984), or placed in the dark for 4 to 8 weeks before light exposure (Gresshoff and Doy,

Received for publication 24 Sept. 1990. Journal Paper no. J-14229 of the Iowa Agriculture and Home Economics Experiment Station, Ames, Iowa. Project no. 2220. Research taken from a dissertation by J. Jaramillo in partial fulfillment of the requirements for a $\mathrm{PhD}$ in horticulture. The cost of publishing this paper was defrayed in part by the payment of page charges. Under postal regulations, this paper therefore must be hereby marked advertisement solely to indicate this fact.

'Graduate Student.

${ }^{2}$ Associate Professor. 1972b; Gulshan et al., 1981). During preliminary experiments, we observed that tomato anthers produced more callus when incubated in the dark, whereas callus exposed to a 16-h photoperiod browned earlier and ceased growth. To achieve our goal of maximizing anther-derived callus production, it became important to determine the optimal dark incubation period.

Three tomato cultivars were chosen to provide anthers in this study. 'L-680A' was selected because $60 \%$ to $80 \%$ of its anthers had produced callus in previous studies. ' $\mathrm{Li}$ cato' and 'Ailsa Craig' were chosen to represent lines that respond poorly to anther culture (Jaramillo and Summers, 1990). Greenhouse-grown plants were watered as needed and fertilized weekly with $300 \mathrm{ppm}$ 20N-20P-20K + microelements (Peters Professional, W.R. Grace, Fogelsville, Pa.). Buds containing anthers at prophase I (leptotene), 1.5 to $1.8 \mathrm{~mm}$ in length, were surface-sterilized for 15 to $20 \mathrm{sec}$ in $70 \%$ ethanol, immersed in $0.5 \%$ sodium hypochlorite for $5 \mathrm{~min}$, and then rinsed four times with sterilized Type I water. Five anthers from each bud were plated on a petri dish (Fisher $6 \times$ $1.5 \mathrm{~cm}$ ) containing $10 \mathrm{ml}$ of $\mathrm{DBM}_{1}, \mathrm{pH} 5.8$ (Gresshoff and Doy, 1972a, 1972b) supplemented with $2 \mathrm{mg}$ 1-naphthaleneacetic acid derived callus.

${ }^{2}$ Error $\mathrm{a}$ and $\mathrm{b}$ were pooled because Error $\mathrm{b}>$ Error $\mathrm{a}$.

*,**Significant at $P=0.05$ or 0.01 , respectively.
(NAA)/liter, $5 \mathrm{mg} \mathrm{N}$-(2-furanylmethyl)-1Hpurin-6-amine (kinetin)/liter, and $6 \mathrm{~g}$ Noble agar/liter. The dishes were wrapped with parafilm, covered with aluminum foil, and placed in a dark growth-chamber held at 26 $\pm 1.5 \mathrm{C}$. A previous 8 -week experiment indicated that anthers cultured in the dark for 0 or 2 weeks produced calli that yellowed and browned when exposed to light, whereas callus produced when dark conditions were longer than 2 weeks remained cream colored (data not shown). Therefore, dark period durations chosen were $2,3,4,5,6,7,8,9$, and 10 weeks. After dark treatment, each plate was exposed to a 16-h photoperiod ( 88 $\mu \mathrm{mol} \cdot \mathrm{s}^{-1} \cdot \mathrm{m}^{-2}$ ) provided by cool-white fluorescent lamps for the duration of the 10week experiment. Culture dishes were distributed at random in a growth chamber as a split-plot design. Tomato cultivars were assigned to main plots, and subplots consisted of the dark-light treatments. The number of anthers producing calli and calli diameters were recorded after 10 weeks. Callus diameter was determined by taking the mean of the polar and equatorial diameters observed in a reticle-equipped Nikon (Tokyo) SMZ-10 stereoscopic microscope. Variance techniques were used to analyze dish mean data.

Zamir et al. (1980) and Ziv et al. (1984) have proposed the use of male sterile antherculture systems as a way to increase the number of tomato anthers producing callus. A simpler method to obtain callus without using cumbersome male sterile systems may be to expose anthers to extended dark periods during culture. In this study, the number of anthers producing callus and callus diameter (Fig. $1 \mathrm{~A}$ and B) increased with prolonged periods of dark exposure. Callus induction increased significantly during the 4th, 6th, and 7th weeks of dark treatment (Table 1). Although $62 \%$ of the fertile anthers were induced to callus after 10 weeks of dark treatment, no significant increase in the number of anthers producing calli was observed after 8 weeks. One cause of low tomato anther calli production in previous studies (Cappadocia and Sree-Ramulu, 1980) may be attributed to the use of a shorter dark treatment. Increasing the length of dark treatment to 8 weeks could increase the number of calli produced by $400 \%$.

Maximizing callus growth is important if calli are to be subdivided for additional treat-

Table 1. Dark period effects and mean squares (MS) for the number and diameter of tomato anther-

\begin{tabular}{|c|c|c|c|c|c|}
\hline \multirow{3}{*}{$\begin{array}{l}\text { Source of } \\
\text { variation }\end{array}$} & \multirow[b]{3}{*}{ df } & \multicolumn{4}{|c|}{ Callus } \\
\hline & & \multicolumn{2}{|c|}{ No. } & \multicolumn{2}{|c|}{ Mean diam (mm) } \\
\hline & & MS & F & MS & $\mathrm{F}$ \\
\hline Replication & 11 & 2.49 & 3.11 & 0.71 & 1.27 \\
\hline Cultivar (C) & 2 & 41.47 & $52.18^{*}$ & 14.23 & $25.41^{* *}$ \\
\hline Error a & 22 & $0.43^{z}$ & & 0.56 & \\
\hline Dark period (D) & 8 & 35.92 & $44.90^{* *}$ & 24.22 & $56.33^{* *}$ \\
\hline$C \times D$ & 16 & 1.05 & 1.31 & 1.52 & $3.53^{* *}$ \\
\hline Error b & 264 & $0.83^{z}$ & & 0.43 & \\
\hline
\end{tabular}



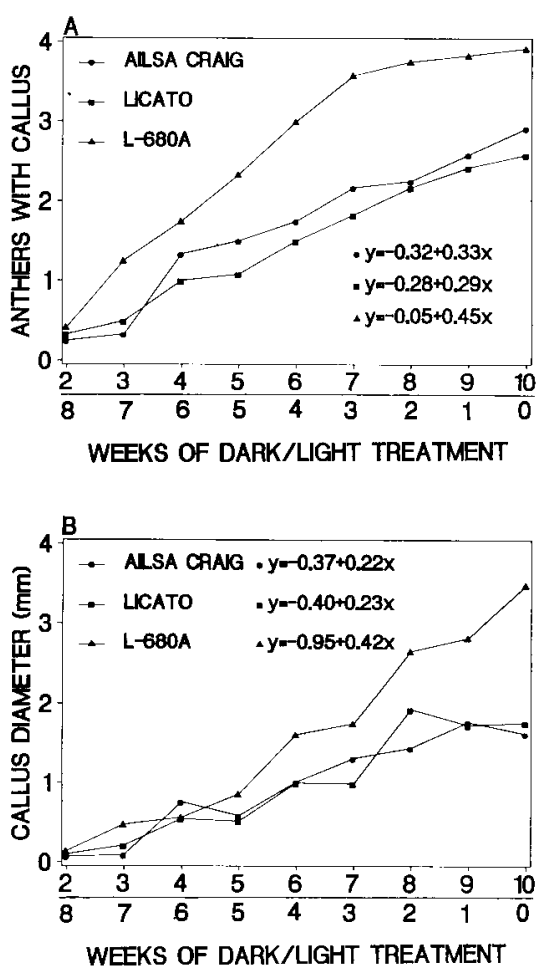

Fig. 1. Mean number of anthers that produced callus (A) and mean diameter of calli in millimeters (B) derived from three tomato cultivars that were incubated under various dark-light periods.

ments. In this study, calli grew faster in the dark (Fig. 1). Calli grown for 10 weeks in darkness were 3.4 times larger than calli exposed to 5 weeks of darkness followed by 5 weeks of light. In general, each week of dark exposure increased callus grown by $0.27 \mathrm{~mm}$. Callus growth did not increase in a uniform manner during this study. Significant increases in callus diameter were noted the 4th, 6 th, and 8th weeks of dark treatment. 'L$680 \mathrm{~A}^{\prime}$ produced 1.5 to 1.8 times more callus that was 1.6 times larger than that of either 'Ailsa Craig' or 'Licato'.

Although the number of anthers producing callus increased as dark period duration increased, the rate of callus growth was reduced if longer-than-optimal dark periods were used. Exposing 'Licato' or 'Ailsa Craig' calli to more than 8 or 9 weeks of darkness reduced growth (Fig. 1), whereas 'L-680A' calli continued to grow throughout the course of the experiment. Linear regression models were significant $\left(R^{2}=0.57\right.$ for the number of anthers producing callus and $R^{2}=0.61$ for callus diameter). Although there is a continuous increase in number and size of callus, this and other studies suggest that calli should be transferred to regeneration medium after 8 weeks of dark treatment (Gresshoff and Doy, 1972b; Gulshan et al., 1981). This practice would significantly increase the number of calli, which may result in an increase in the production of haploid/dihaploid tomato plants.

\section{Literature Cited}

Cappadocia, M. and K. Sree-Ramulu. 1980. Plant regeneration from in vitro cultures of anthers and stem internodes in an interspecific hybrid, Lycopersicon esculentum L. $\times$ L. peruvianum Mill. and cytogenetic analysis of the regenerated plants. Plant Sci. Lett. 20:157-166.

Cornejo-Martin, M.J., A.M. Mingo-Castel, and E. Primo-Millo. 1979. Organ redifferentiation in rice callus: Effects of $\mathrm{C}_{2} \mathrm{H}_{4}, \mathrm{CO}_{2}$, and cytokinins. Z. Pflanzenphysiol. 94:117-123.

Fraser, R.S., U.E. Loening, and M.M. Yeoman. 1967. Effect of light on cell division in plant tissue cultures. Nature (London) 215:873.

George, E.F. and P.D. Sherrington. 1984. Plant propagation by tissue culture. Exegetics Ltd., England.

Gresshoff, P.M. and C.H. Doy. 1972a. Haploid Arabidopsis thaliana callus and plants from anther culture. Austral. J. Biol. Sci. 25:259-264.

Gresshoff, P.M. and C.H. Doy. 1972b. Development and differentiation of haploid Lycopersicon esculentum (tomato). Planta 107:161-170.

Gulshan, Y., T.M. Varghese, and D.R. Sharma. 1981. Studies on anther cultures of tomato $L y$ copersicon esculentum Mill. Biol. Plant. (Praha) 23:414-420.

Huxter, T.J., T.A. Thorpe, and D.M. Reid. 1981. Shoot initiation in light and dark-grown tobacco callus. The role of ethylene. Physiol. Plant. 53:319-326

Jaramillo, J. and W. Summers. 1990. Tomato anther callus production: Solidifying agent and concentration influence the induction of callus. J. Amer. Soc. Hort. Sci. 115:1047-1050.

Kut, S.A., J.E. Bravo, and D.A. Evans. 1984 Tomato, p. 247-289. In: P.V. Ammirato, D.A. Evans, W.R. Sharp, and Y. Yamada (eds.). Handhook of plant cell culture: Crop species. vol. 3. Macmillan, New York.

Niizeki, H. and K. Oono. 1968. Induction of haploid rice plant from anther culture. Proc. Jpn. Acad. 44:554-557.

Noth, M.H. and W.O. Abel. 1971. Zur entwicklung haploider pflanzen aus unreifen mikrosporen verschiedener Nicotiana arten. Z. Pflanzenszucht. 65:277-284.

Sopory, S.K. and S.C. Maheswhari. 1976. Development of pollen embryoids in anther cultures of Datura innoxia. I. General observations and effects of physical factors. J. Expt. Bot. 27:49-57.

Sunderland, N. 1971. Anther culture: A progress report. Sci. Prog. 59:527-549.

Zamir, D., R.A. Jones, and N. Kedar. 1980. Anther culture of male sterile tomato (Lycopersicon esculentum Mill.) mutants. Plant Sci. Lett. 17:353-361.

Ziv, M., D. Hadary, N. Kedar, and G. Ladizinsky. 1984. Lycopersicon esculentum: Trifoliate plants recovered from anther cultures of heterozygous Tftf plants. Plant Cell Rpt. 3:10-13. 